\title{
Fischer-type gold(I) carbene complexes stabilized by aurophilic interactions
}

\author{
Daniela I. Bezuidenhout ${ }^{a^{*}}$, Belinda van der Westhuizen ${ }^{a}$, Amos J. Rosenthal ${ }^{b}$, Michael \\ Wörle $^{b}$, David C. Liles ${ }^{a}$, Israel Fernández ${ }^{c^{*}}$
}

\begin{abstract}
The synthesis and structure of rare acyclic alkoxy- and aminocarbene complexes of gold(I) are reported, including a novel ferrocenophane dinuclear biscarbene complex. X-Ray diffraction analyses and DFT calculations reveal that these complexes are stabilized by genuine aurophilic interactions.
\end{abstract}

Interest in the structure of molecular gold complexes increased rapidly since 1970 due to the unexpected observation of intraand intermolecular attractive forces between two linear gold(I) atoms. ${ }^{1}$ Although the interaction between positively charged gold cations should result in a remarkable Coulomb repulsion, a good number of complexes with intra- and intermolecular equilibrium distances in the range from $2.50-3.50 \AA$ has been reported. $^{2}$ This phenomenon, referred to as aurophilicity, opened a new arena for the structural engineering of gold compounds. ${ }^{3}$ Aurophilic bonding can be classified in three categories: unsupported, semi-supported and fully supported interactions. ${ }^{2} \mathrm{Au} \cdots \mathrm{Au}$ interactions can be separated by one (semi-supported) or two (fully supported) multi-atomic bridges. In the absence of such a bridge, interactions are unsupported. As stated by Gorin and Toste, the integration of theoretical and synthetic studies of $\mathrm{Au}(\mathrm{I})$ is required for deeper understanding of the fundamental properties of gold complexes in order to illuminate further avenues for study. ${ }^{4}$ Due to the unprecedented success of Au-N-heterocyclic carbenes, as well as acyclic diaminocarbene complexes in the field of homogeneous catalysts for organic transformations, the structures of a variety of 'prototypes' have been determined. ${ }^{5}$ However, examples of Fischer-type (i.e. mono-heteroatom substituted) acyclic gold(I) carbene complexes are not common. ${ }^{6}$ Moreover, the presence of aurophilic interactions in these complexes remains scarcely explored so far. For these reasons, we report herein a series of novel acyclic Fischer-type Au(I) carbene complexes which exhibit genuine aurophilic interactions as clearly confirmed by $\mathrm{X}$-Ray diffraction and computational studies.

Following the reaction conditions reported by Raubenheimer and co-workers, ${ }^{6}$ heteroaryl gold(I) chloro-monocarbene complexes 1-5 were synthesized by direct transmetallation ${ }^{7}$ from their tungsten( 0 ) analogues ${ }^{8}$ in good to excellent yields using $\mathrm{ClAu}$ (tht) (tht = tetrahydrothiophene) in tetrahydrofuran (THF) at $-5^{\circ} \mathrm{C}$. Not unexpectedly, the ${ }^{13} \mathrm{C}$ NMR spectra of the gold(I) complexes generally displayed an upfield shift of the carbene carbon atom of $c a$. $50 \mathrm{ppm}$ compared to the tungsten pentacarbonyl analogues (see SI). Interestingly, the carbon resonances for the rest of the atoms in the complexes, as well as the proton shifts, are shifted downfield, indicative of greater ring- and heteroatom involvement towards the stabilization of the electrophilic carbene carbon atom.

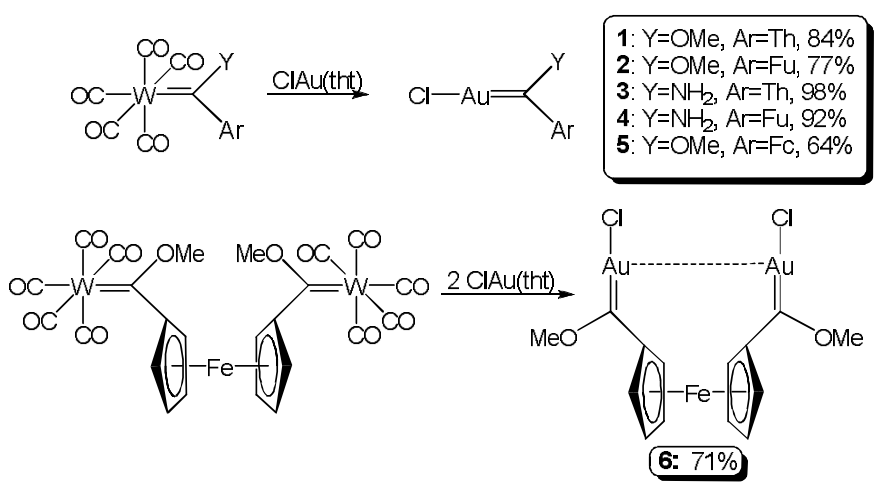

Scheme 1 Preparation of complexes 1-6.

Crystals were obtained by layering a THF solution of the complex with hexane at $5^{\circ} \mathrm{C}$. The $\mathrm{Au}-\mathrm{C}_{\text {carbene }}$ bond distances in the complexes 1-5 (Figure 1) fall within the typical range of an $\mathrm{sp}^{2}$-hybridized carbon atom bonded to a gold centre trans to a chlorine atom $(1.96-2.02 \AA) .{ }^{6 e, f, 9}$ Similar to the $\mathrm{M}-\mathrm{C}_{\text {carbene }}$ bond lengths observed for their group 6 Fischer carbene counterparts, ${ }^{10}$ the carbon-gold bond distances in the methoxycarbene complexes are slightly shorter as compared to the amine-stabilized carbenes. This is due to the well-known higher $\pi$-donor ability of the nitrogen atom compared to oxygen. In all the complexes, the gold atom is linearly coordinated with the $\mathrm{C}-\mathrm{Au}-\mathrm{Cl}$ bond angle varying between $173^{\circ}$ and $179^{\circ}$. Moreover, the alkoxy group of complexes 1, 2, 5 and 6 adopts the so-called anti-conformation, ${ }^{11}$ where the methyl group is oriented towards the transition metal analogously to group 6 Fischer alkoxycarbene complexes.

Apart from that, an important feature is exhibited by complexes 1-5 in the solid state, namely they present, with the adjacent molecule, ${ }^{12} \mathrm{Au} \cdots$ Au distances in the range from 3.093 to 3.307 $\AA$. This agrees with the classification of unsupported $\mathrm{Au}-\mathrm{Au}$ interaction for these species. ${ }^{2}$ In complexes $\mathbf{1}$ and $\mathbf{2}$ each gold centre participates in two such interactions (as indicated in Figure 1) thus infinite chains of linked molecules are formed. 
Taking into account this finding, we decided to prepare the novel ferrocenophane dinuclear biscarbene complex 6 (see Scheme 1), where the ferrocen-1,1'-diyl bridge should enforce a closer proximity between the gold atoms. Indeed, for complex 6, a shorter $\mathrm{Au} \cdots \mathrm{Au}$ distance was found in the solid state (3.035 $\AA$, Figure 1), thus confirming the semi-supported type of aurophilic interaction for this complex.

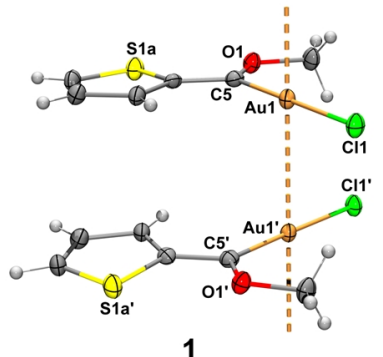

1

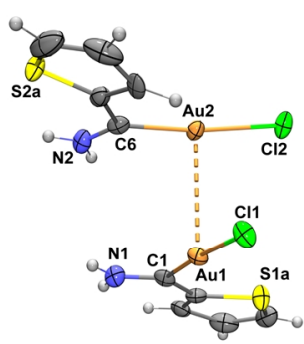

3

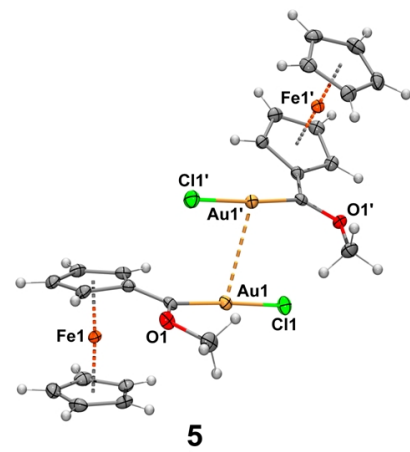

5
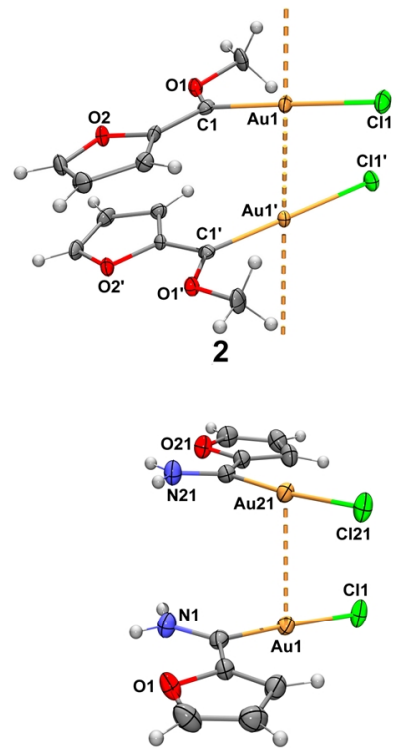

4

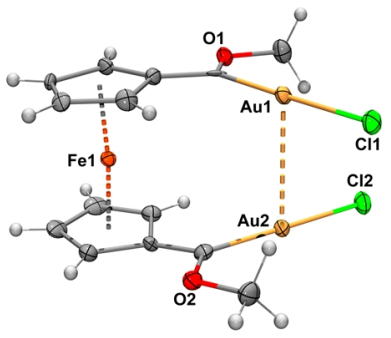

6
Fig. 1 Ortep/PovRay diagrams of 1-6 with adp ellipsoids shown at the $50 \%$ probability level. For 3, a third molecule has been omitted. Au $\cdots \mathrm{Au}$ interactions $(\AA): \quad 13.28083(11) ; \quad 2 \quad 3.3073(2) ; \quad 3 \quad 3.2179(7) ; \quad 4 \quad 3.0925(2) ; \quad 5 \quad 3.2885(2) ;$ 6 3.0354(10). Au- $\mathrm{C}_{\text {carbene }}$ bond distances $(\AA)$ : 1 1.970(4); 2 1.974(3); 3 1.985(6), 1.984(5); 4 1.979(3), 1.977(3); 5 1.977(3); 6 1.970(7), 1.960(6).

From the above structural study, it becomes clear that these novel gold(I) carbene complexes are stabilized by aurophilic interactions. To gain more insight into the nature of the $\mathrm{Au} \cdots \mathrm{Au}$ interaction in these species, Density Functional Theory (DFT) calculations were carried out using the dispersion-corrected M06 functional (M06/def2-TZVP level) ${ }^{13}$ on the unsupported and semi-supported complexes $\mathbf{2}$ and $\mathbf{6}^{14}$ As shown in Figure 2, the computed $\mathrm{Au} \cdots \mathrm{Au}$ distance for complex 2 in the gas-phase (3.319 $\AA$ ) concurs very well with the experimental distance in the solid state (3.307 $\AA$ ). However, the agreement is not that good for complex 6, very likely due to packing forces in the solid state. Despite this, the computed $\mathrm{Au} \cdots \mathrm{Au}$ distance in the latter compound is clearly shorter than in complex $\mathbf{2}$, as a consequence of the semi-supported $\mathrm{Au}-\mathrm{Au}$ interaction in this species.
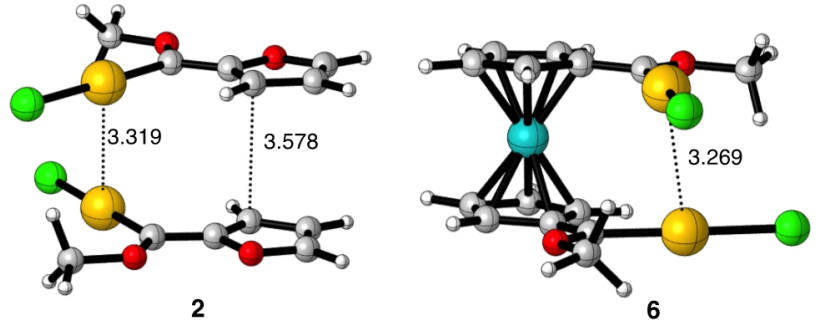

Fig. 2 Optimized (M06/def2-TZVP level) structures of complexes 2 and 6. Bond distances are given in angstroms.

The nature of the $\mathrm{Au} \cdots \mathrm{Au}$ bonding in complexes $\mathbf{2}$ and $\mathbf{6}$ was analysed with the help of the Atoms in Molecules (AIM) and Natural Bond Orbital (NBO) methods. ${ }^{13}$ As depicted in Figure 3 , the AIM method clearly reveals for both compounds the occurrence of a bond critical point (BCP) located at the midpoint between the two gold(I) atoms which is associated with a bond path running between these two atoms. These topological analyses therefore confirm the existence of an interaction between the $\mathrm{Au}(\mathrm{I})$ atoms. The computed electron density $(\rho)$ and ellipticity $(\varepsilon)$ values at the $\mathrm{Au} \cdots \mathrm{Au}$ BCP's are

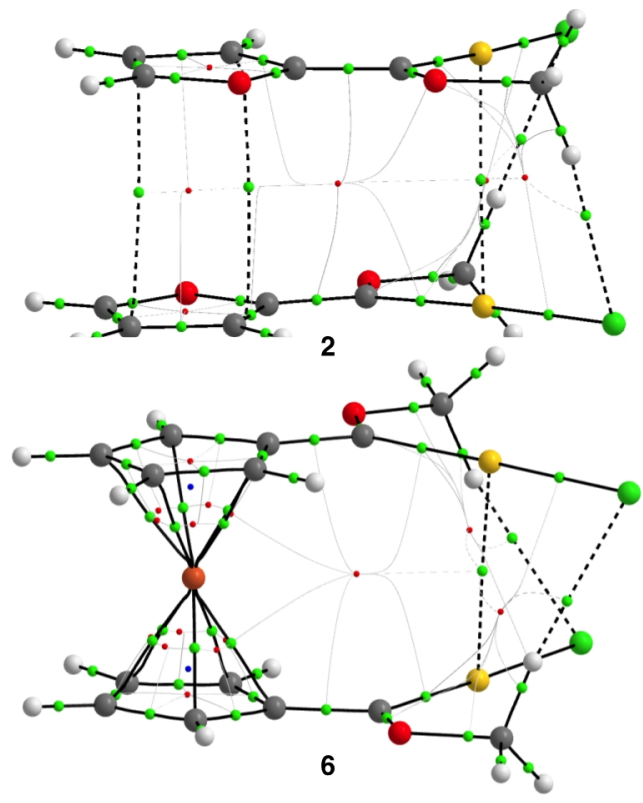

Fig. 3 AIM analyses of complexes 2 and 6. BCP's are shown as green spheres.

similar in both complexes $\left(\rho=0.014\right.$ e $\AA^{-3}, \varepsilon=0.029$ vs $\rho=$ $0.013 \mathrm{e} \AA^{-3}, \varepsilon=0.028$ for 6 and 2 , respectively) thus indicating a similar type of interaction. In addition, the corresponding Au$\mathrm{Au}$ Wiberg Bond Index (0.14 and 0.15 for 2 and $\mathbf{6}$, respectively) are also similar and comparable to the values found for related (NHC) AuCl dimers. ${ }^{15}$

Interestingly, the Second Order Perturbation Theory (SOPT) of the NBO method indicates that the aurophilic interaction is characterized by the donation of electron density from a doubly occupied $d$ atomic orbital of one $\mathrm{Au}(\mathrm{I})$ to an empty $p$ atomic orbital of the adjacent metal (see Figure 4). The associated SOPT energy computed for $\mathbf{2}$ and $\mathbf{6}$ is quite remarkable $\left(\Delta \mathrm{E}^{(2)}=\right.$ -9.4 and $-9.3 \mathrm{kcal} / \mathrm{mol}$, respectively), thus reflecting the importance of these aurophilic interactions in the global 
stabilization of the novel Fischer type Au(I)-carbene complexes described herein.

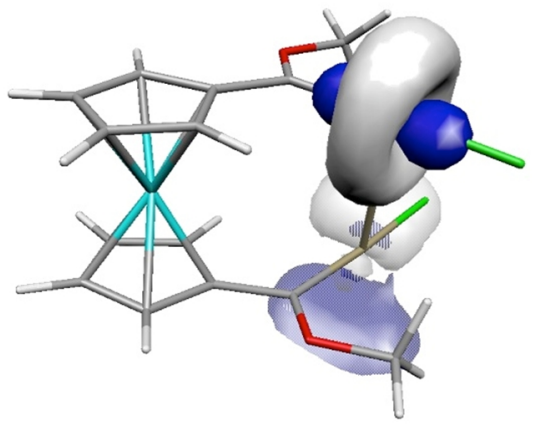

Fig. 4 NBO-molecular orbitals responsible for the $\mathrm{Au} \cdots \mathrm{Au}$ interaction in complex 6 (isosurface value of $0.035 \mathrm{au}$ ).

In summary, uncommen examples of Fischer-type gold(I) carbene complexes are prepared by direct transmetallation reaction from their correponding tungsten(0) carbene complexes and $\mathrm{ClAu}($ tht). By means of X-ray diffraction analyses and DFT calculations, stabilizing aurophilic interactions in Fischer-type carbene complexes are characterized for the first time. Indeed, the $\mathrm{Au} \cdots \mathrm{Au}$ interaction allows the preparation of the first Fischer-type ferrocenophane biscarbene complex containing two $\mathrm{Au}(\mathrm{I})$ atoms. Futher work aimed at the preparation and reactivity of related (semi)supported carbene complexes exhibiting aurophilic interactions is in progress in our laboratories.

\section{Acknowledgements}

This work is supported by the National Research Foundation, South Africa (D.I.B., Grant number 76226), and the Spanish MICINN and CAM (I.F., Grants CTQ2010-20714-CO201/BQU, Consolider-Ingenio 2010, CSD2007-00006, S2009/PPQ-1634).

\section{Notes and references}

${ }^{a}$ Chemistry Department, University of Pretoria, Private Bag X20, Hatfield 0028, South Africa. E-mail: daniela.bezuidenhout@up.ac.za; Fax:+27(0)12-420-4687; Tel: +27-(0)12-420-2626.

${ }^{b}$ Department of Chemistry and Applied Biosciences, ETH Zürich, Zürich 8093, Switzerland.

${ }^{c}$ Departamento de QuímicaOrgánica I, Facultad de Química, Universidad Complutense, 28040-Madrid, Spain.E-mail: israel@quim.ucm.es; Tel: $+34-913945155$.

$\dagger$ Electronic Supplementary Information (ESI) available: Synthetic procedures and analytical data; data tables for single crystal X-ray structural analysis; Computational details and Cartesian coordinates and energies for the optimised compounds 2 and 6. CCDC numbers for complexes 1 - 6: 962460, 962459, 962461, 963795, 962458 and 962457. See DOI: $10.1039 / \mathrm{c} 000000 \mathrm{x} /$

1 (a) R. J. Puddephatt, The Chemistry of Gold, Elsevier, Amsterdam, 1978; (b) O. Crespo, Modern Supramolecular Gold Chemistry. Ed. A. Laguna, Chapter 2, Wiley-VCH, Weinheim, 2008; (c) S.-G. Wong and W. H. E. Schwarz, J. Am. Chem. Soc., 2004, 126, 1266; (d) P. Pyykkö, Chem. Soc. Rev., 2008, 37, 1967; (e) M. Andrejić and R. A. Mata, Phys. Chem. Chem. Phys., 2013, 15, 18115.

2 (a) H. Schmidbaur and A. Schier, Chem. Soc. Rev., 2012, 41, 370; (b) P. Schwerdtfeger and M. Lein, Gold Chemistry. Current Trends and Future Directions. Ed. F. Mohr, Wiley-VCH, Weinheim, 2009; (c) V. W.-W. Yam and E. C.-C. Cheng, Chem. Soc. Rev., 2008, 37, 1806.
3 (a) H. Schmidbaur, W. Graf and G. Müller, Angew. Chem., Int. Ed. Engl., 1988, 27, 417; (b) H. Schmidbaur, Gold Bull., 2000, 33, 3.

4 D. J. Gorin and F. D. Toste, Nature, 2007, 446, 395-403.

5 (a) G. D. Frey, R. D. Dewhurst, S. Kousar, B. Donnadieu and G. Bertrand, J. Organomet. Chem., 2008, 693, 1674-1682; (b) H. G. Raubenheimer and S. Cronje, Chem. Soc. Rev., 2008, 37, 1998-2011; (c) H. G. Raubenheimer, S.A.J., 2012, http://hdl.handle.net/10019.1/ $\underline{81278}$

6 (a) R. Aumann and E. O. Fischer, Chem. Ber., 1981, 114, 1853; (b) E. O. Fischer, M. Böck and R. Aumann, Chem. Ber., 1983, 116, 3618; (c) E. O. Fischer and M. Böck, Monatsh. Chem., 1984, 115, 1159; (d) M. Fañanás-Mastral and F. Azno, Organometallics, 2009, 28, 666; (e) C. E. Strasser, S. Cronje and H. G. Raubenheimer, New J. Chem., 2010, 34, 458; (f) U. Schuber, K. Ackermann and R. Aumann, Cryst. Struct. Commun., 1982, 11, 519.

7 For a review on the transmetalation reaction from group 6 carbene complexes, see: (a) M. Gómez-Gallego, M. J. Mancheño and M. A. Sierra, Acc. Chem. Res. 2005, 38, 44. For a computational study, see: (b) I. Fernández, M. J. Mancheño, R. Vicente, L. A. López, and M. A. Sierra, Chem. Eur. J. 2008, 14, 11222.

8 (a) B. van der Westhuizen, J. M. Speck, M. Korb, J. Friedrich, D. I. Bezuidenhout and H. Lang, Inorg. Chem., 2013, submitted; (b) E. O. Fischer, W. Held, F. R. Kreiß1, A. Frank and G. Huttner, Chem. Ber., 1977, 111, 656-666; (c) R. Streubel, S. Priemer, F. Ruthe, P. G. Jones and D. Gudat, Eur. J. Inorg. Chem., 1998, 575-578.

9 (a) G. Banditelli, F. Bonati, S. Calogero, G. Valle, F.E. Wagner and R. Wordel, Organometallics, 1986, 5, 1346; (b) B. Bovio, A. Burini and B.R. Pietroni, J. Organomet. Chem., 1993, 452, 287; (c) S.-W. Zhang, R. Ishii and S. Takahashi, Organometallics, 1997, 16, 20; (d) H.M.J. Wang, C.Y.L. Chen and I.J.B. Lin, Organometallics, 1999, 18, 1216; (e) L. Weber, G. Dembeck, P. Lonneke, H.-G. Stammler and B. Neumann, Organometallics, 2001, 20, 2288; (f) C.E. Strasser, E. Stander-Grobler, O. Schuster, S. Cronje and H.G. Raubenheimer, Eur. J. Inorg. Chem., 2009, 1905; (g) H. Seo, B.P. Roberts, K.A. Abboud, K.M. Merz Jr. and S. Hong, Org. Lett., 2010, 12, 4860; (h) H. Seo, D.R. Snead, K.A. Abboud and S. Hong, Organometallics, 2011, 30, 5725; (i) L.-A. Schaper, K. Öfele, R. Kadyrov, B. Bechlars, M. Drees, M. Cokoja, W.A. Herrmann and F.E. Kuhn, Chem. Commun., 2012, 48, 3857.

10 (a) B. van der Westhuizen, P. J. Swarts, I. Strydom, D. C. Liles, I. Fernández, J. C. Swarts and D. I. Bezuidenhout, Dalton Trans., 2013, 42, 5367; (b) B. van der Westhuizen, P. J. Swarts, L. M. van Jaarsveld, D. C. Liles, U. Siegert, J. C. Swarts, I. Fernández and D. I. Bezuidenhout, Inorg. Chem. 2013, 52, 6674-6684.

11 (a) I. Fernández, F. P. Cossío, A. Arrieta, B. Lecea, M. J. Mancheño and M. A. Sierra, Organometallics 2004, 23, 1065; (b) D. M. Andrada, M. E. ZoloffMichoff, I. Fernández, A. M. Granados and M. A. Sierra, Organometallics 2007, 26, 5854; (c) D. A. Valyaev, R. Brousses, N. Lugan, I. Fernández and M. A. Sierra, Chem. Eur. J. 2011, 17, 6602; (d) N. Lugan, I. Fernández, R. Brousses, D. A. Valyaev, G. Lavigne and N. A. Ustynyuk, Dalton Trans. 2013, 42, 898.

12 In the asymmetric unit cell of the crystal structure of 3 there are 3 molecules of the complex of which just two have an aurophilic interaction. See SI.

13 See Computational Details in the Supplementary Material.

14 For a critical review on quantum chemical calculations to characterize aurophilic interactions, see reference $1 \mathrm{~d}$ and references therein.

15 L. Ray, M. M. Shaikh and P. Ghosh, Inorg. Chem. 2008, 47, 230. 